\title{
E-Government Adoption and Security Website Framework for Martyrs and Wounded of Popular Mobilization Forces and Iraqi Militaries
}

\author{
Mohammed Rajih Jassim \\ Department of Production Engineering \& Metallurgy, University of Technology ,Baghdad, Iraq \\ mrj_1212@yahoo.com
}

\begin{abstract}
In this paper, the limitation of the existing E-Government system is highlighted, followed by the introduction of the new e-service framework that handles the e-government system in the offline mode. This framework can manage complaints and transactions in an effective manner. The current study is significant since an unbiased assessment of the loopholes was conducted in accordance with the information security guidelines. Furthermore, all possible vulnerabilities of the system were assessed to evaluate the actual impacts of the information security guidelines. Some suggestions have been recommended to improve the information security of Egovernance systems for Martyrs and Wounded of Popular Mobilization Forces and Iraqi Militaries. Nevertheless, the current project framework has been adopted from the relevant research works performed earlier. The framework design involves two stages: (1) design of a flexible website for Martyrs and Wounded of Popular Mobilization Forces and Iraqi Militaries. In other words, we would like to provide a robust egovernment service to Iraqi government; and (2) improve system security and prevent man-in-the-middle (MiMT) attack. The significance of this study is to reduce the claim processing time for the martyrs and wounded of popular mobilization forces and Iraq military. Furthermore, it will increase the reply time from the departments and the clients to reply for their inquiries.
\end{abstract}

Index Terms-E-government, citizen, methodology, design, research, information and Internet

\section{INTRODUCTION}

There are several advantages associated with an e-government system, such as improved productivity and fast execution[1]. Electronic transactions are popular because the number of human errors could be reduced. However, combining all government services in one web service portal could provide convenience to users [1]. It can interact with government agencies efficiently as the number of paperwork is greatly reduced. The electronic government is defined as the establishment of policies and communication channels necessary to manage and control information through the implementations of policies and laws in order to shorten the processing time[2]. In 2008, the United Nations (UN) and some governments have created new services to improve the Iraqi government's infrastructure [3]. However, the new system is not ideal for storing information due to data leakage. Meanwhile, there is a massive delay in the development of e-government in Iraq [4]. This is because e-mail services are becoming less popular, and there is a lack of awareness amongst citizens about the importance of e-government. In 2013-2017, there was a war between Iraq and the Islamic State of Iraq and Syria (ISIS). Popular Mobilization Forces and Iraqi militaries have requested for relevant medical articles for medical assistance [5]. However, the security of these websites is questionable [6].

Currently, Internet is widely used to assess a particular information [7]. The Internet service, however, may not be stable at every moment [8]. In some instances, clients leave 
home and need to communicate with certain staff and collect information as soon as possible, so using the web may not work properly through operating communication processes. However, from the survey conducted by the Middle East government, the egovernment framework can be adopted in developing countries such as Iraq [8]. One of the developing countries, namely UAE, has attempted to implement an e-government system within its ministries before formalizing the system [9]. The first e-government system in Dubai was implemented in 2003. [10]. The Iraqi government attempted the similar strategy as that adopted in UAE. The emblematic embargo of the Iraqi government is revealed in Fig 1.

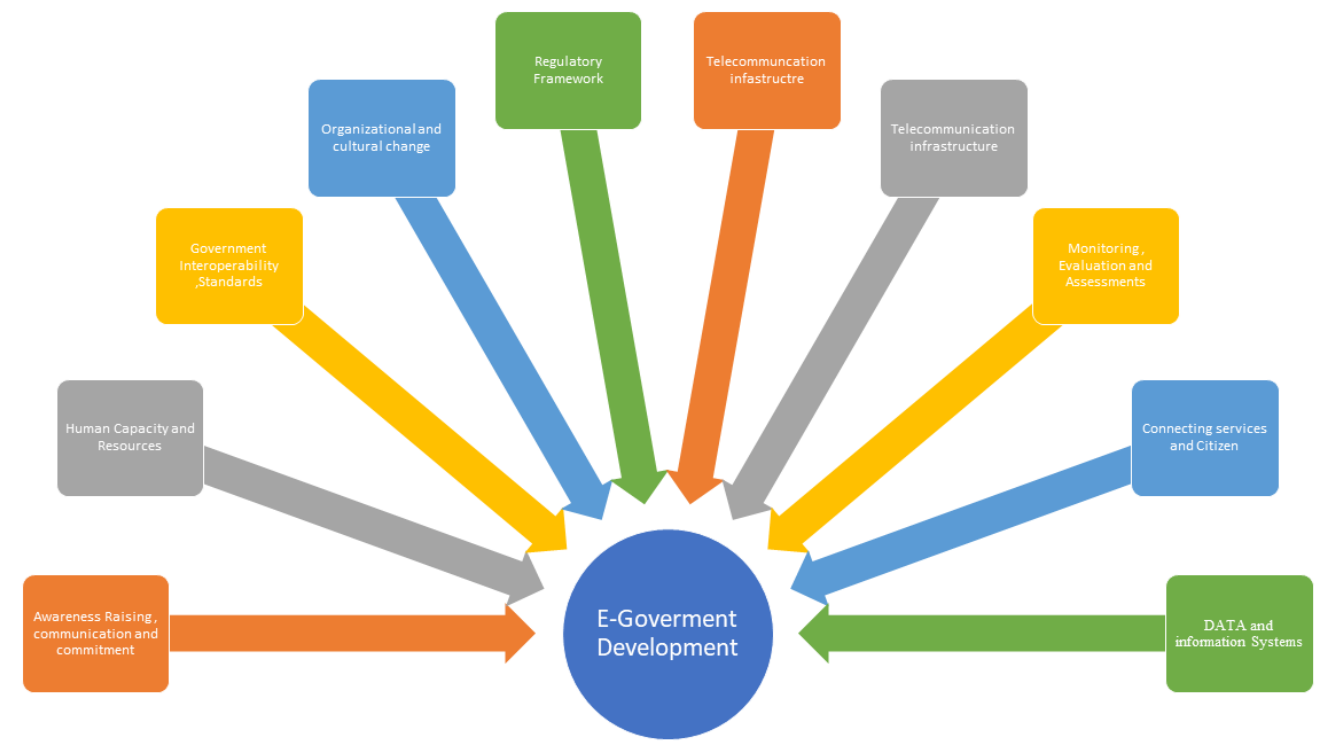

Fig. 1. Circular of E-GOVERnMent IN IRAQ [11]

Both Egypt and KSA have started to implement the e-government system since its introduction in 2000 [12]. Due to the war occurred in 2003, the infrastructure in Iraq has been destroyed. Thanks to the assistances provided by the United Nations and the Federation of Nations, there were some improvements after one year [13]. Nevertheless, the execution of large-scale development work is hindered due to the security concern. However, the advantages of the e-government in Iraq will be as:

Eliminating the office paper work archive system and replace it with the electronic archiving system for its high flexibility in performance and the ability to correct errors at high speed and processing data for more than one hand at the specified time and place. The ease of managing and monitoring the different departments of the organization as if it were one central unit. Speed in making appropriate decisions based on accurate and direct information. Simplification of procedures, speed of delivery and performance of services. Eliminating bureaucracy and facilitating the division of labor and specialization. The research and development department for the Ministry of Higher Education and Scientific Research in Iraq was ranked as the first department in the implementation and follow-up of the e-citizen project in April 2016. The evaluation of this important project was supervised by the General Secretariat of the Council of Ministers of the citizen. However, [6] the main contribution of this paper narrowed in both complaint management and martyr transaction of the new e-government system with security aspects are proposed. Additionally, it is recommended to improve the infrastructures in Iraq. Anyway, the government databases such as Rivest, Shamir and Adleman (RSA) [14] have been upgraded to improve the confidentiality of public and personal information. 


\section{RESEARCH GAP}

Manuscripts Organizations that adopt the e-management projects must know that there are several critical factors that must be analyzed. Analysis of these factors reflects in one way or another the success or failure of these projects. This leads us to the fact that every project in electronic management has its own conditions and possibilities for success and failure. In addition, due to the increase in the number of martyrs and wounded after overwhelming victories over the ISIS, there is a need to facilitate the transactions of the martyrs and the wounded crowd. However, there is no service in the form of an electronic government so far to meet their special requirement, whether the allowance of salaries, or compensation material or any moral support. This leads us to reflect the research problem with the following research questions:

Q1: To what extent do Popular Mobilization Forces and Iraqi militaries understand the critical success factors in adopting the e-government system.

Q2: Do Popular Mobilization Forces and Iraqi militaries realize the benefits of moving to E-government and data privacy by using crypto aspect?

\section{Framework Desgin}

\section{A. Customized website design for E-government}

Although the proposed program is based on the development of the offline as an initial prototype, it is not only appropriate to focus on state services in online but not supportive. The problem of the concept is resolved by filing complaints and trades related to injury and death. And our apps should experience similar problems.

However, the website has three main components: client, webserver and backend server. The server should have the ability to manage thousands of client's requests per minute. For that, we have deployed the Tomcat server and connect it with MySQL server in the same machine, as shown in Fig.2, and Fig. 3, respectively. In addition, our server spec was intel i3 CPU with four Gigabyte of RAM, and 1 Terabyte of storage.

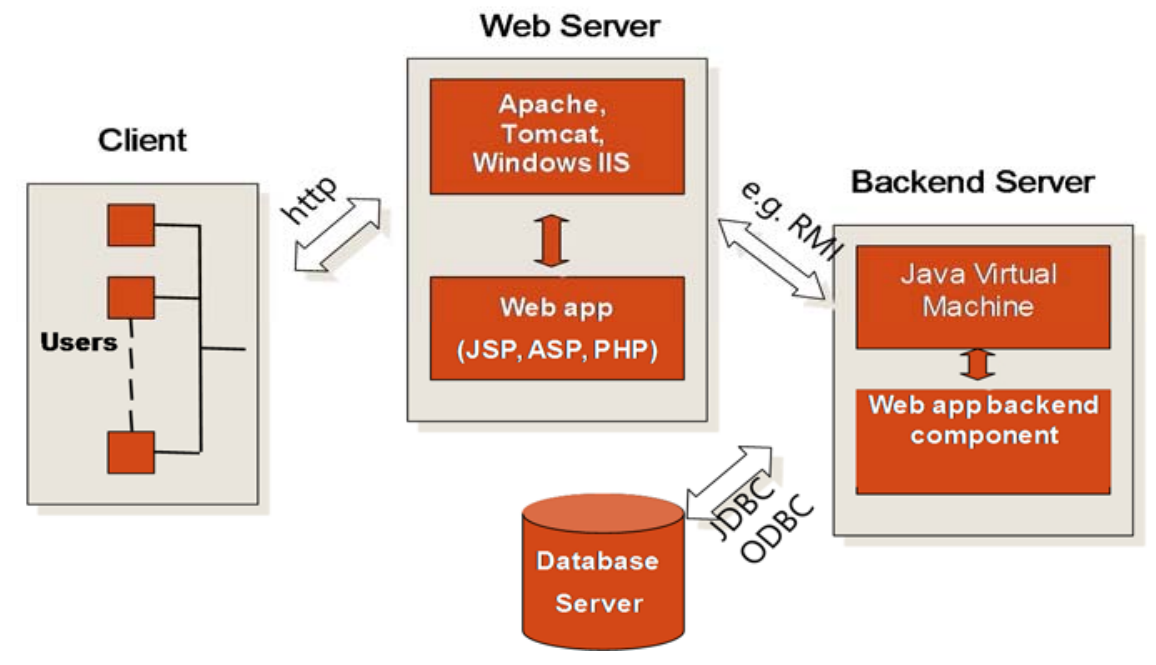

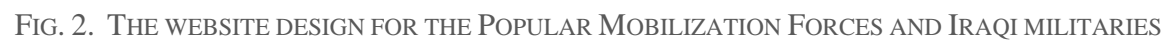




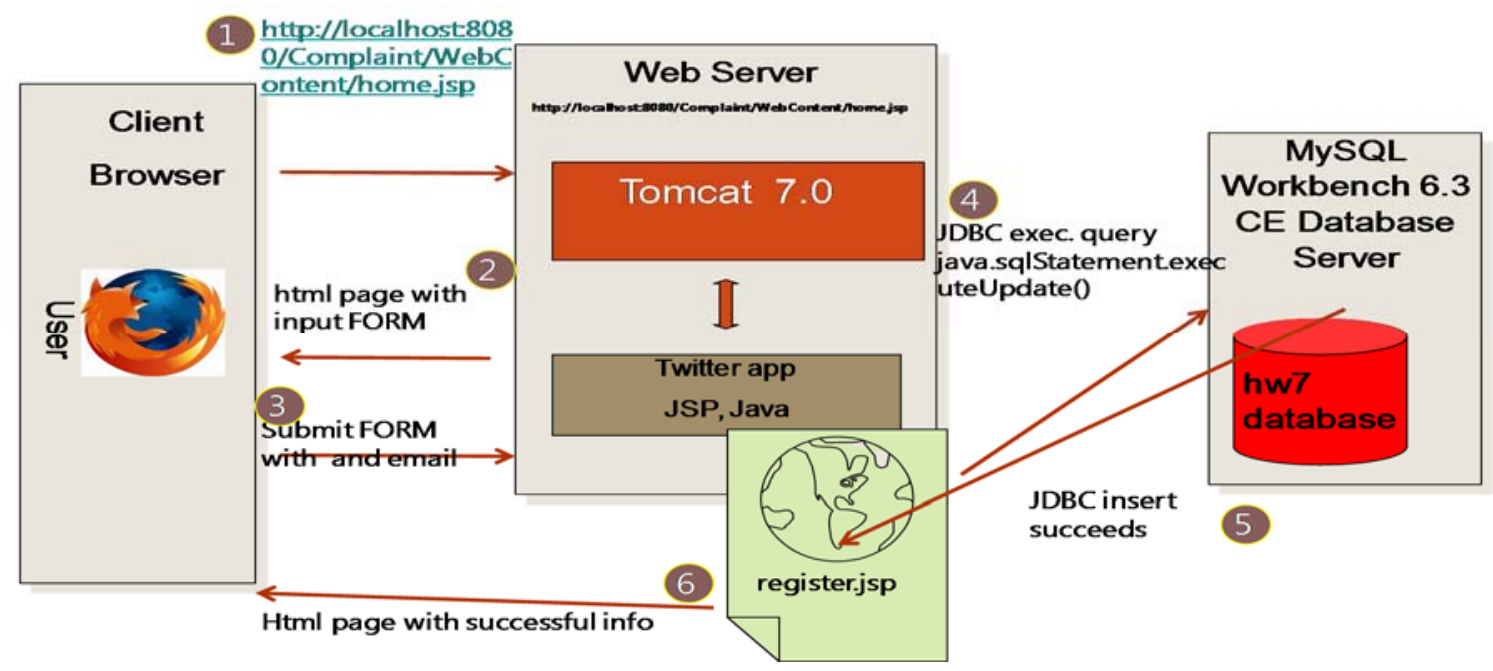

Fig. 3. The WEBSITE REgISTRATION EXAMPLE - REgISTER.JSP

\section{B. Connect JSP to database}

Connecting tomcat server with MySQL is essential and indispensable and for each user will secure by custom username and password as shown in Fig. 4. For example, if we store Popular Mobilization Forces and Iraqi militaries families member names for complaints, for example, in a table, it may order sent to another table, and we need to link clients to review their complaints. Needless to say, this will give us a repeat of names and information of users in the order table, especially if there is more than one request for each person as shown in Figure 5. MySQL Workbench 6.3 CE [15], is a more feasible solution to reorganize the record of the client names and all their entered information.

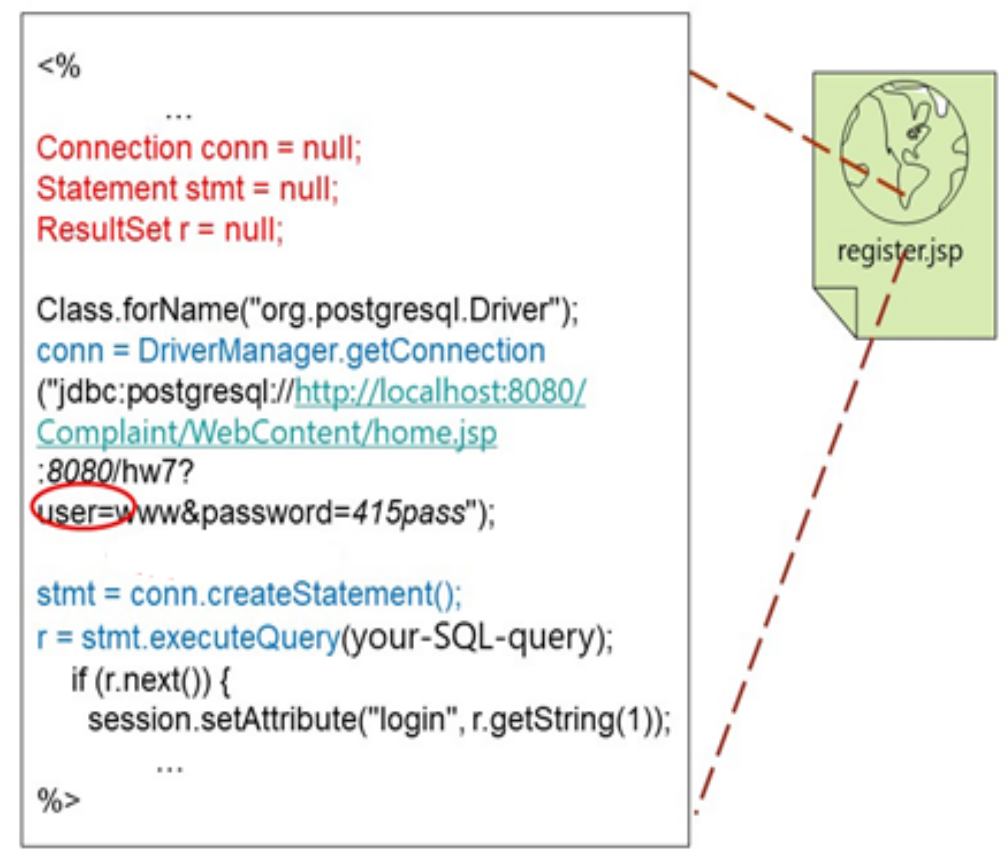

FIG. 4. AUTHENTICATION PROSS FOR DESIGNED E-GOVERNMENT WEBSITE 


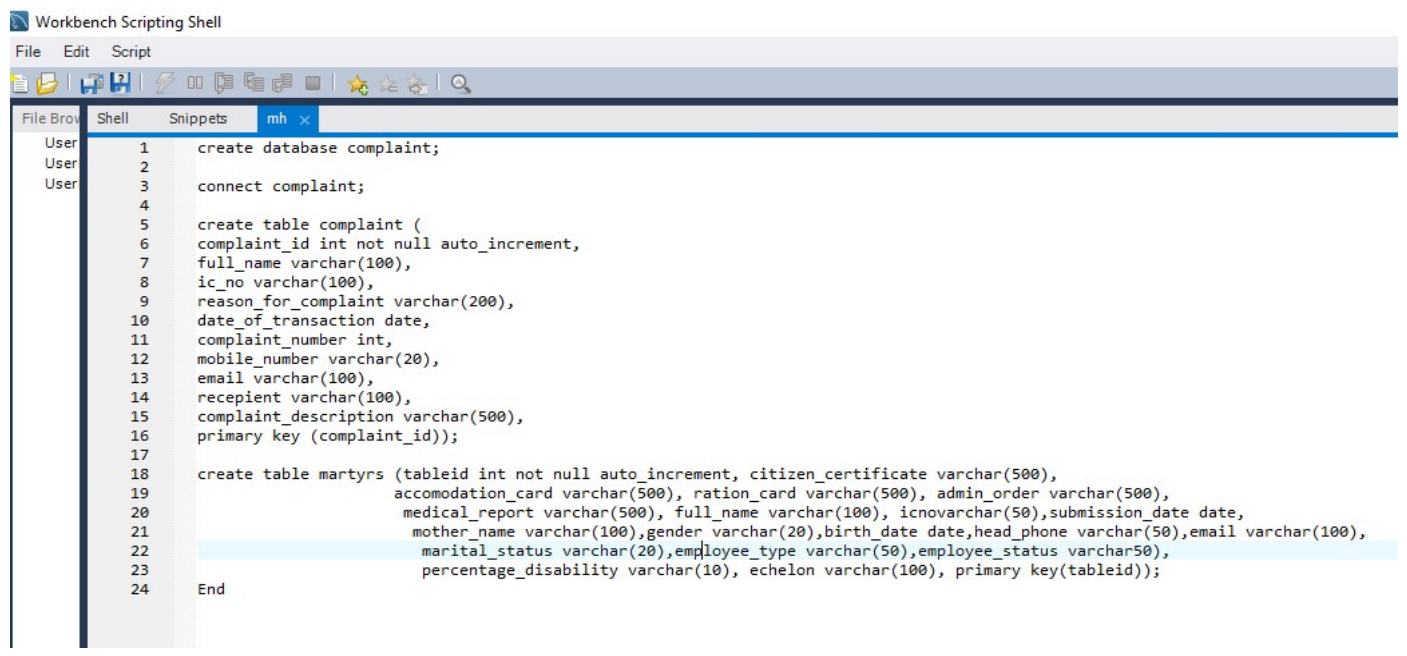

FIG. 5. PSEUDO CODE FOR USER INFORMATION IN MYSQL

\section{Secure web browser}

Information security is important for all government agencies. Therefore, the confidentiality of information must be properly managed. There are two major types of securities, i.e. reliability and information. Relevant instructions and safeguard systems must be installed and maintained to ensure data integrity. Effective public administration is vital in improving the delivery of public services using information technology. In the current work, an active web server using RSA was proposed to view or delete targeted messages for protection purposes. Instead of using the internet security messages, the uncertainty algorithm called "Kill Sha-1" was used to protect communications. If the message reaches an unsecured connection, it would be no longer protected, and the message would appear on the search server. This message might be changed or deleted. Current website and e-service in Iraq lack the security and privacy and these issues are tabulated in Table 1 . Furthermore, the difference between our website and standard Iraqis web sites is found in Fig 6.

TABLE 1. IRAQ WEB SERVICES THREATS AND WEAKNESS

\begin{tabular}{|l|l|}
\hline \multicolumn{1}{|c|}{ Threat } & \multicolumn{1}{c|}{ Description } \\
\hline Message Alteration: & $\begin{array}{l}\text { The message content is changed in some } \\
\text { way. }\end{array}$ \\
\hline Message Snooping: & $\begin{array}{l}\text { An unauthorized entity "sees" the message } \\
\text { (perhaps processing it). }\end{array}$ \\
\hline Impersonation: & $\begin{array}{l}\text { an entity pretends to be another entity, } \\
\text { sending or receiving unauthorized messages. }\end{array}$ \\
\hline Message Replay: & $\begin{array}{l}\text { Can involve both partial and complete } \\
\text { message replay. }\end{array}$ \\
\hline Man-in-the-Middle: & $\begin{array}{l}\text { The MITM impersonates both the sender } \\
\text { and the recipient. }\end{array}$ \\
\hline Denial of Service & Death by a thousand cuts \\
\hline
\end{tabular}




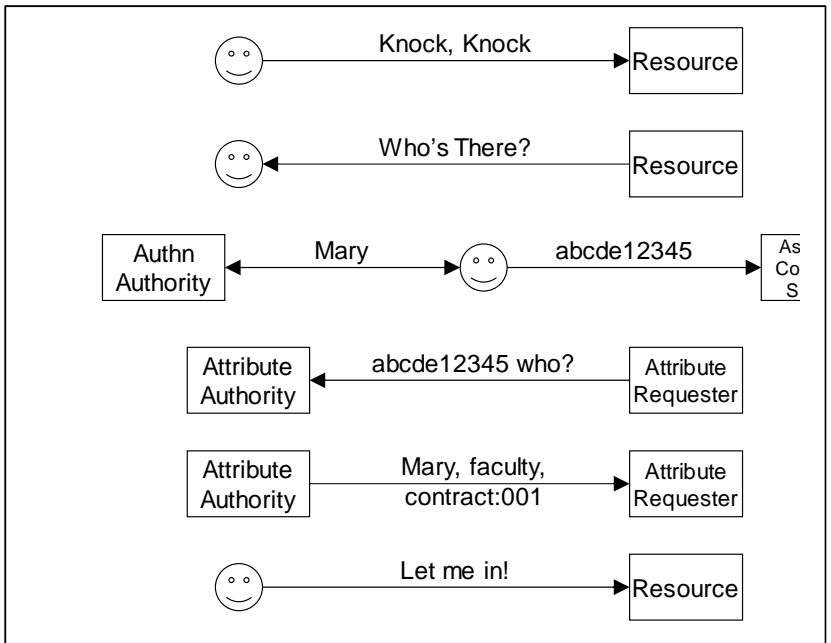

Fig. 7. High LeVel ARChiteCtURE FOR RSA IN OUR WEBSite

However , the procedure steps for the proposed algorithm are shown bellow:

1. Designing a website for that attached the government.

2. Adopting RSA algorithm for more confidentiality.

3. Implementing in java environment.

4. Reason to choose java language.

5. Component of java that is used for RSA algorithm implementation in website.

6. Implementation details.

7. Final layout website design implementation with RSA algorithm.

\section{IMPLEMENTATION AND RESULTS}

Iraqi society is suffering from major issues such as loss of personal electronic data due to hacking activities. Existing guidelines are simply insufficient to ensure the security of government data. These security issues are addressed in the current work. Electric governance is so great that this management is a weak source of infrastructure, and people are not fully aware of the concept. Due to the popularities of web design and common security screens, those relevant web pages on the Internet may break.

\section{Website design current implementation}

We have created new sites for managing resources at the ministries of injuring Iraqi mobilization and Iraqi forces. These sites were linked to the Iraqi main web server. Therefore, our site is dynamic as citizens could place complaint(s) to top managers by accessing these service locations (as shown in Fig 8).

When filing a complaint, some information must be specified, including a brief description of the complaint (as shown in Fig.9).

When we want to help life and injuries and as soon as possible we will prepare the site design and the importance of the subject, and we offer light and deadly dead families to their homeland too expensive, spiritual and diabolical, and help save the work of everyday people who have long been waiting for the site, then the grandchildren and the damaged area, as shown in Fig.10 


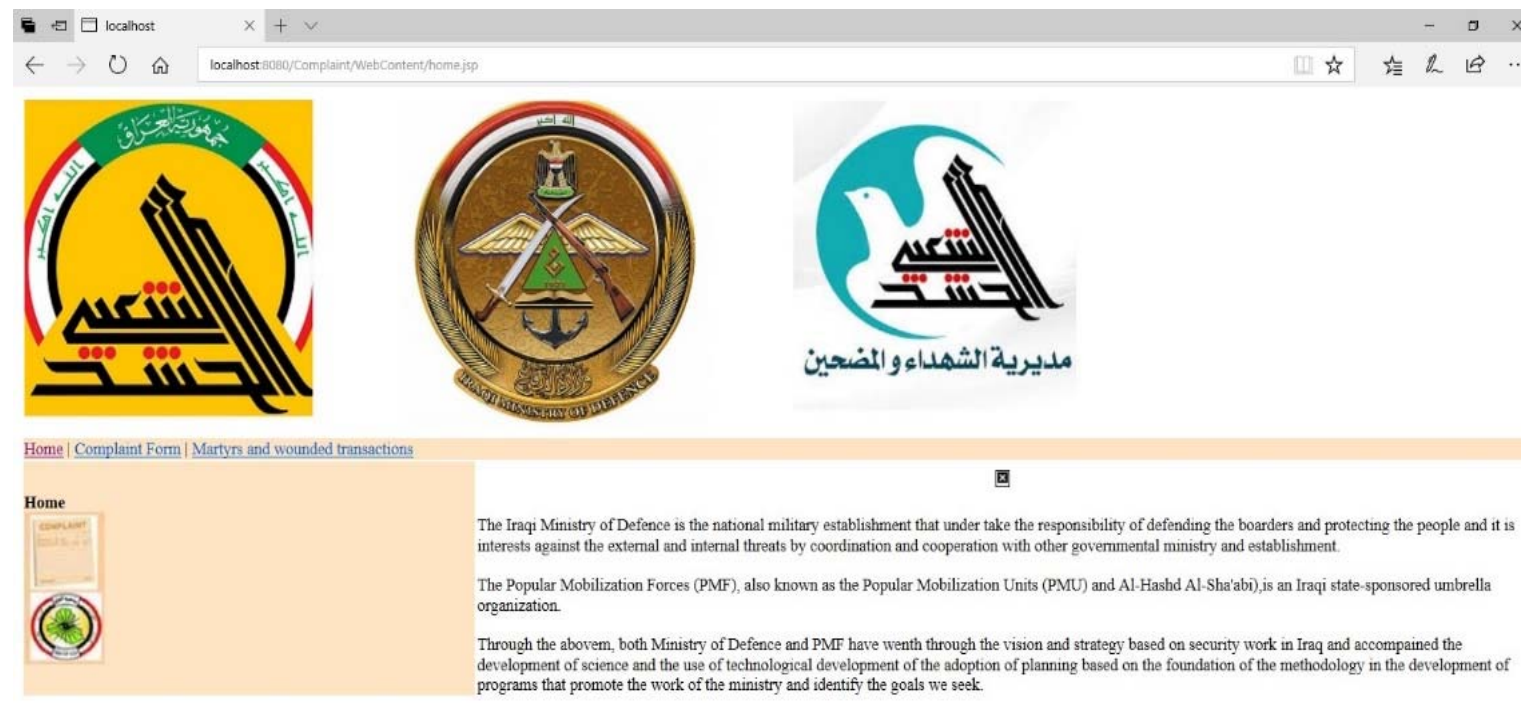

Fig. 8. CURREnT E GOVERnMENT WEBSite
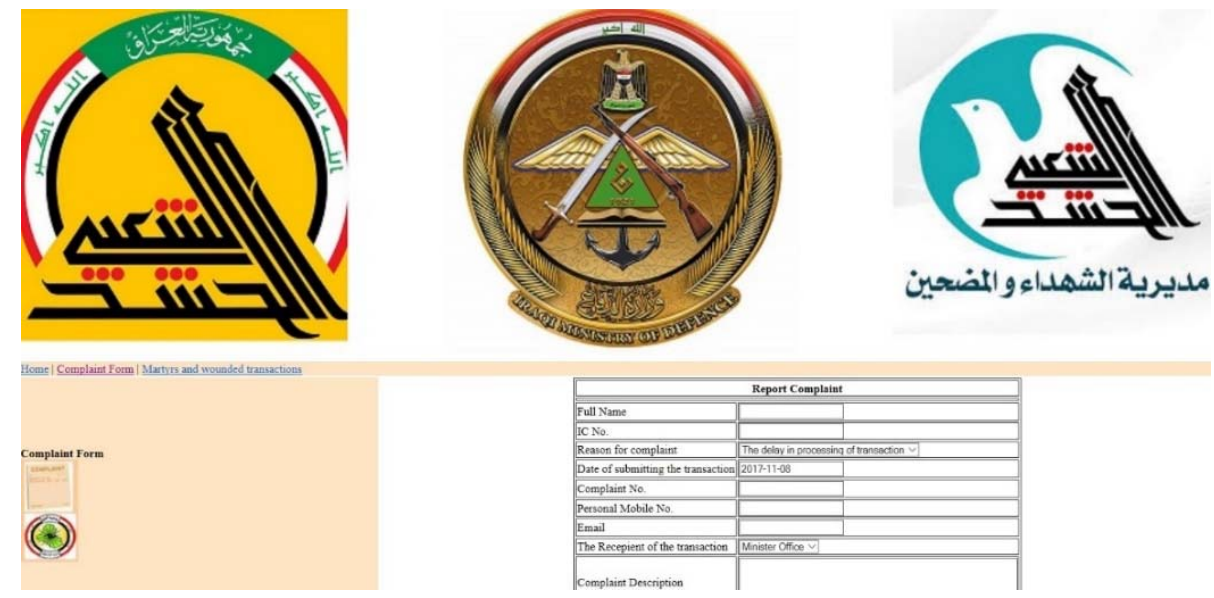

Fig. 9. COMPLAint REgistration Form
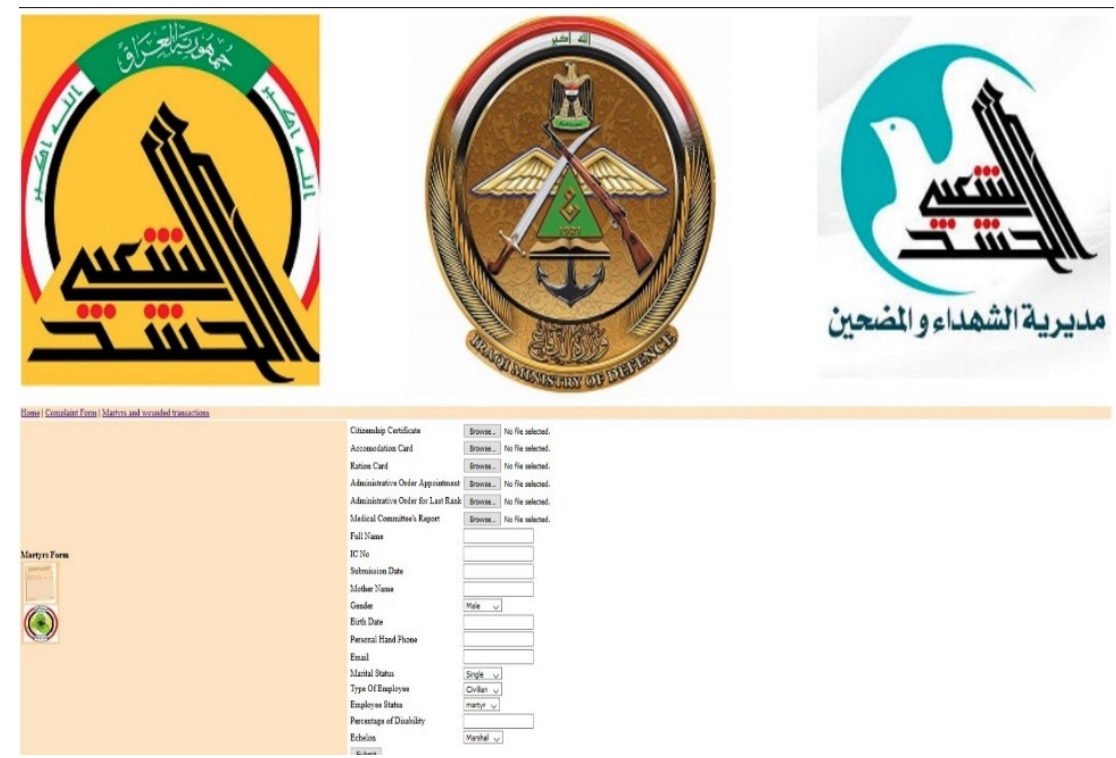

Fig. 10. MARTYR AND WOUNDED SECURE TRANSACTION 
However, our RSA encryption should perform better than AES and DES security algorithms. Nevertheless, today's cryptographic schemes do not scale well, and thus are not suited for the increasingly large sets of data they are used on. For instance, the security guarantees currently known for RSA encryption -- the most commonly used type of encryption scheme -- degrade linearly in the number of users and cipher texts. Hence, larger settings (such as the scenario of E-government encrypting all existing email traffic) may enable new and more efficient attacks. To maintain a reasonable level of security in larger scenarios, RSA key lengths must be chosen significantly larger, and the scheme becomes very inefficient. Besides, a switch in RSA key lengths requires an update of the whole public key infrastructure.

\section{CONCLUSION}

A new framework for improving the efficiency of the current e-government system has been proposed. A unique approach has been adopted to deal with complaints and martyrs. A new electronic services framework has been designed to reduce the number of civilian casualties in Iraq and reduce the number of non-communicable casualties. By using this framework, peoples can access information at any time via the e-government services without using the Internet. Therefore, the efficiency of the e-government system can be enhanced. The development of reliable and accurate encryption protocols across devices should be further explored.

\section{REFERENCES}

[1] S.-Y. Hung, C.-M. Chang, and S.-R. Kuo, "User acceptance of mobile e-government services: An empirical study,” Government Information Quarterly, vol. 30, no. 1, pp. 33-44, 2013.

[2] J. M. Shafritz, E. W. Russell, and C. Borick, Introducing public administration: Routledge, 2015.

[3] A. Whitmore, "Using open government data to predict war: A case study of data and systems challenges," Government Information Quarterly, vol. 31, no. 4, pp. 622-630, 2014.

[4] S. Shareef, "The adoption of cloud computing for e-government initiative in regional governments in developing countries." pp. 453-461.

[5] R. Hoencamp, E. Vermetten, E. C. Tan, H. Putter, L. P. Leenen, and J. F. Hamming, "Systematic review of the prevalence and characteristics of battle casualties from NATO coalition forces in Iraq and Afghanistan,” Injury, vol. 45, no. 7, pp. 1028-1034, 2014.

[6] T. J. Abaas, A. S. Shibghatullah, and M. M. Jaber, "Use Information Sharing Environment Concept to Design Electronic Intelligence Framework for Support E-Government: Iraq as Case Study," Advances in Computing, vol. 4, no. 1, pp. 22-24, 2014.

[7] U. Sivarajah, Z. Irani, and V. Weerakkody, "Evaluating the use and impact of Web 2.0 technologies in local government,” Government Information Quarterly, vol. 32, no. 4, pp. 473-487, 2015.

[8] I. I. Imran, A. S. Elameer, and R. Al-Hamdani, "Design and Development of a MOOC for Academic Institution in Iraq." p. 174.

[9] A. M. Aladwani, "Corruption as a source of e-Government projects failure in developing countries: A theoretical exposition,” International Journal of Information Management, vol. 36, no. 1, pp. 105-112, 2016.

[10] K. Alqasa, and E. M. Al-Matari, "Technology adoption and innovation of E-Government in Republic of Iraq,” Asian Social Science, vol. 11, no. 3, pp. 135, 2014.

[11] R. Titah, and H. Barki, "E-government adoption and acceptance: A literature review," International Journal of Electronic Government Research (IJEGR), vol. 2, no. 3, pp. 23-57, 2006.

[12] J. S. Ismael, T. Y. Ismael, and G. Perry, Government and politics of the contemporary Middle East: Continuity and change: Routledge, 2015.

[13] T. K. Al Hilfi, R. Lafta, and G. Burnham, "Health services in Iraq," The Lancet, vol. 381, no. 9870, pp. 939-948, 2013.

[14] L. Nwosu, B. Alese, A. Thompson, and O. Obe, "An Attribute-Based Signature using rivest shamir adleman scheme." pp. 380-386.

[15] M. Mokhsin, A. Aziz, A. Shahuddin, A. Lokman, and M. Idris, "WEB-BASED VIRTUAL LEARNING ENVIRONMENT (EMOVILE) WITH EMOTIVE INTERFACE FEATURE,” Journal of Fundamental and Applied Sciences, vol. 9, no. 4S, pp. 430-448, 2017. 